\title{
An exploration investigation on measuring the impact of information technology on bullwhip effect on supply chain management
}

\author{
Vahid Shahabi", Mohammad Emami, Maliheh Sadat Monnavari and Fatemeh Ghods
}

Department of Industrial Management, Islamic Azad University, Semnan Branch, Semnan, Iran

\begin{tabular}{l}
\hline C H R O N I C L E \\
\hline Article history: \\
Received June 12, 2013 \\
Received in revised format \\
25 August 2013 \\
Accepted October 262013 \\
Available online \\
October 20 2013 \\
\hline Keywords: \\
Bullwhip effect \\
Fuzzy DEMATEL \\
Supply chain management
\end{tabular}

\section{A B S T R A C T}

Information technology plays an important role on the success of different organizations. In today's competitive environment, there is a need to reduce the cost of products by increasing productivity and quality of products and services. Bullwhip effect is one of the most important issues influencing production planning reducing the efficiency of production planning by increasing unwanted materials, etc. Bullwhip effect occurs for many reasons such as lack of good demand estimation, poor communication between vendors and suppliers, etc. In this paper, we present an empirical investigation based on DEMATEL technique to find the effect of information technology on reducing the bad consequences of bullwhip effect. The study first uses systems dynamic to build a cause-andeffect relationship between different factors influencing bullwhip effect and then using fuzzy DEMATEL, the effect of information technology on bullwhip effect has been confirmed.

(C) 2014 Growing Science Ltd. All rights reserved.

\section{Introduction}

Bullwhip is one of the most important issues, which could influence the performance of production planning, significantly (Hoffman, 2000; Kim et al., 2006). Bullwhip effects are created when supply chain members process the demand input from their immediate downstream member in generating their own forecasts (Lee et al., 1997). In supply chain management, one of the most important problems, which need significant amount of effort to deal with, is to understand how to quantify and alleviate the effect of bullwhip effect - the phenomenon in which information on demand is distorted while moving upstream (Luong, 2007). Machuca and Barajas (2004) performed an investigation to study the impact of electronic data interchange on reducing bullwhip effect and supply chain inventory costs. Miragliotta (2006) investigated different layers and mechanisms in supply chain management by introducing a new taxonomy for the bullwhip effect.

Aggelogiannaki and Sarimveis (2008) presented an adaptation method for the online identification of lead time in production-inventory control systems. In this survey, the tuning parameters are updated in real time to improve the efficiency of the system based on the lead-time estimate. Caplin (1985)

* Corresponding author.

E-mail addresses: vahidshahabi1366@yahoo.com (V. Shahabi)

(C) 2014 Growing Science Ltd. All rights reserved.

doi: $10.5267 /$ j.uscm.2013.10.003 
developed a general theory of the aggregate implications of $(S, s)$ inventory policies and explained that $(\mathrm{S}, \mathrm{s})$ policies could add to the variability of demand, with the variance of orders exceeding the variance of sales.

Supply chain management has been recognized as the management of key business processes across the network of organizations, which comprise the supply chain (Day, 1984). While many have considered the advantage of a process approach for managing the business and the supply chain, most do not good description about what processes are to be considered, what sub-processes and activities are contained in each process, and how the processes exchange information with each other and with the traditional functional silos (Lo \& Chen, 2012). Croxton et al. (2001) provided strategic and operational explanation of each of the eight supply chain processes detected by members of The Global Supply Chain Forum, as well as descriptions of the interfaces among the processes and an instance of how a process approach can be applied within an organization. Chou et al. (2004) explained the trend in supply chain management by studying Web technologies that transform and streamline the supply chain management. Croom (2005) concentrated on the developments in ebusiness system adoption and deployment in support of supply chain management. Demeter et al. (2006) examined the connection between strategy and SCM and analyzed how the strategy of focal firms determined the supply chain (SC) configuration and management practices used between SC parties. The results supported the proposition that the connection between strategy and SCM was very strong.

Disney et al. (2004) explained that a suitable objective function was linearly associated with the bullwhip and inventory variance amplification ratios and then optimized the PIC system for various weightings of order rate and inventory level variance. They highlighted two kinds of the objective functions, one where "the golden ratio" can be applied to determine the optimal gain in the inventory and WIP feedback loop and another, which permits the complete range of possible solutions to be visualized.

Geary et al. (2006) detected 10 published causes of bullwhip, all of which are capable of elimination by re-engineering the supply chain and suggested some evidence on the present "health" of a family of supply chains, and pinpoint much good practice. Ha and Krishnan (2008) outlined a hybrid method, incorporating multiple methods into an evaluation process, in order to choose competitive suppliers in a supply chain. It enables a buyer to do single sourcing and multiple sourcing by calculating a combined supplier score (CSS), which accounts for both qualitative and quantitative factors that influence on supply chain performance. Lu and Wang (2008) analyzed the characteristic of network economy and proposed a topological structure of it. They described the interactive coefficient matrix of network economy to explain the effect of network economy.

DEMATEL was first presented at Battelle Memorial Institute of Geneva Research Center and it has been applied for various complicated problems in the world such as famine, energy, environmental protection, etc. (Fontela \& Gabus, 1976).

DEMATEL is one of the well-known multi criteria decision making (MCDM) techniques and maintains the capability of converting the qualitative designs for quantitative analysis (Lee et al., 2011). The primary objective of DEMATEL is to convert the relationships among different criteria, causal dimensions from a very complex system into an understandable structural framework of that system (Dalalah et al., 2011). All criteria of a system, directly or indirectly, are mutually associated with each other in a general reciprocal system. Najmi and Makui (2010), for instance, provided hierarchical approach for measuring supply chain performance using AHP and DEMATEL methodologies. Sofiyabadi et al. (2012) presented an integrated balanced score card combined with DEMATEL technique to prioritize different alternatives for SC implementation. 
In this paper, we present an empirical investigation to study the effect of information technology on reducing the bad consequences of bullwhip effect. The study uses systems dynamic to build a good cause and effect form and using fuzzy DEMATEL, the study detects important factors reducing bullwhip effect.

\section{The proposed study}

We first present details of the fuzzy logic needed in this paper.

\subsection{Fuzzy-logic}

Many organizations adopted group decisions to determine a solution, group decision means to reach an agreement through dialogue among many experts, and in this case, an acceptable decision needs to be adopted. Of course, in such decision associated with complex systems, assessment by experts or decision-makers about a qualitative criteria object will be presented, always couched in language. The theory of fuzzy collection can be implemented to measure vague concepts based on unreal (personal) judgments. Table 1 demonstrates change the vague judge to fuzzy triangle numbers.

\section{Table 1}

The correspondence of linguistic terms and values

\begin{tabular}{ll}
\hline Linguistic values & Linguistic terms \\
\hline$[0.75,1,1]$ & Very high influence(VH) \\
{$[0.5,0.75,1]$} & High influence(H) \\
{$[0.25,0.5,0.75]$} & Low influence (L) \\
{$[0,0.25,0.5]$} & Very low influence (VL) \\
{$[0,0,0.25]$} & No influence (NO) \\
\hline
\end{tabular}

Fuzzy triangle number can be a regular triplets of the form of $(1, m, n)$ or $1 \leq \mathrm{m} \leq \mathrm{n}$. For both fuzzy triangle numbers $A_{1}=\left\{l_{1}, m_{1}, r_{1}\right\} \quad A_{1}=\left\{l_{2}, m_{2}, r_{2}\right\}$, the arithmetic operations are performed as follows,

$$
\begin{aligned}
& A_{1}+A_{2}=\left(l_{1}+l_{2}, m_{1}+m_{2}, r_{1}+r_{2}\right) \\
& A_{1}-A_{2}=\left(l_{1}-l_{2}, m_{1}-m_{2}, r_{1}-r_{2}\right) \\
& A_{1} \otimes A_{2}=\left(l_{1} l_{2}, m_{1} m_{2}, r_{1} r_{2}\right) \\
& \lambda A_{1}=\left(\lambda l_{1}, \lambda m_{1}, \lambda r_{1}\right),(\lambda>0)
\end{aligned}
$$

In recent years, various types of defuzzy techniques have been used (Opricovic \& Tzeng, 2003). In the meantime, the especial unknown and instable environment where fuzzy numbers are applied by considering suitable defuzzy technique. This study implements changing the fuzzy data into determined values (CFCS) proposed by Opricovic and Tezeng (2003) to de-fuzzy. Based on the process of CFCS method, first, right and left values are determined with a minimum and maximum fuzzy based on the fuzzy numbers based on the group evaluating and then the final definite number are measured in the form of average weight based on membership subject.

\subsection{The Fuzzy DEMATEL steps:}

1.Specify evaluation factors according to expert committee's opinion and research background,

2.Determine each factor influences on whole system, according to expert's opinion. To do so, we use discussed wordy expressions in Table 2 and Fig. 1. Then, we used CFC method (Eqs. 1-9) to convert the fuzzy results into crisp values. 
Table 2

The correspondence of linguistic terms and values

\begin{tabular}{ccccccc}
\hline Linguistic values & {$[0.75,1,1]$} & {$[0.5,0.75,1]$} & {$[0.25,0.5,0.75]$} & {$[0,0.25,0.5]$} & {$[0,0,0.25]$} \\
\hline Linguistic terms & Very high influence $(\mathrm{VH})$ & High influence $(\mathrm{H})$ & $(\mathrm{L})$ Low influence & Very low influence (VL) & No influence (NO) \\
\hline
\end{tabular}

$X L_{i j}^{k}=\left(L_{i j}^{k}-\min _{1 \leq k \leq k}^{k}\right) / \Delta_{\min }^{\max }$

Fig. 1. Fuzzy triangle numbers

$X M_{i j}^{k}=\left(M_{i j}^{k}-\min _{1 \leq k \leq k}^{k}\right) / \Delta_{\min }^{\max }$

$X r_{i j}^{k}=\left(r_{i j}^{k}-\min _{1 \leq k \leq k}^{k}\right) / \Delta_{\min }^{\max }$

$\Delta_{\min }^{\max }=\max _{i j}^{k}-\min L_{i j}^{k}$

$X l s_{i j}^{k}=\frac{X m_{i j}^{k}}{\left(1+X m_{i j}^{k}-X l_{i j}^{k}\right)}$

$X r s_{i j}^{k}=\frac{X r_{i j}^{k}}{1+X r_{i j}^{k}-X m_{i j}^{k}}$

$X_{i j}^{k}=\left[X l s_{i j}^{k}\left(1-X l s_{i j}^{k}\right)+X r s_{i j}^{k} \cdot X r s_{i j}^{k}\right] /\left(1+X r s_{i j}^{k}-X l s_{i j}^{k}\right)$

$B N P_{i j}^{k}=\min L_{i j}^{k}+X_{i j}^{k} \Delta_{\min }^{\max }$

$a_{i j}=\frac{1}{k} \sum_{k}^{1 \leq k \leq k} B N P_{i j}^{k}$

$\mathrm{A}=\left[\mathrm{a}_{\mathrm{ij}}\right]$ is direct relations matrix of experts opinions.

3. Calculate total relations matrix T- I where $\mathrm{I}$ is an identity matrix $n \times n$ and $T=\left[t_{i j}\right]$ representing the elements indicating the direct and indirect impacts of factor $i$ on factor $j$. Now, matrix $T$ is the indicator of general relationships between each pair factor in the system. Matrix $D$ is the normalized matrix $D=\left[d_{i j}\right], 0 \leq d_{i j} \leq 1$. 


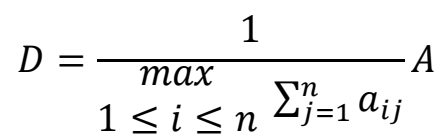

$T=D(I-D)^{-1}$

4. Calculate row summation and column summation of $\mathrm{T}$ matrix $-i$ row summation is indicator of all direct and indirect effects of $i$ factor on all other factors and so can call $r_{i}$ as the impacting degree. $C_{j}$ is similarly, the column summation and we can call it as influenced degree of $j$ factor.

$\begin{aligned} r_{i} & =\sum_{1 \leq i \leq n} t_{i j} \\ C_{j} & =\sum_{1 \leq i \leq n} t_{i j}\end{aligned}$

Therefore, when $i=j, r_{i}+C_{i}$ shows both the influence of which $i$ factor can have on other factors of system and also the impacts of other factors of system on $i$ factor. So, $r_{i}+C_{i}$ show the significant degree of $i$ factor in whole system, and $r_{i}-C_{i}$ indeed shows the influence of $i$ on system. If $r_{i}-C_{i}$ is positive, $i$ factor belong to the cause group and if $r_{i}-C_{i}$ is negative, $i$ factor belong to the effect group.

5. Demonstrate the diagram of factors influencing on $r_{i}-C_{i}$ and $r_{i}+C_{i}$ bases. This diagram is drawn by $\left(r_{i}+C_{i}, r_{i}-C_{i}\right)$ coordinate (Huang, 2009).

\section{System dynamics}

System dynamics is a technique for understanding the behavior of complex systems over time and it deals with internal feedback loops and time delays, which influences the behavior the entire system. What makes using system dynamics totally different from other techniques for studying complex systems is the approach of feedback loops and stocks and flows (Forrester, 1961, 1994). Fig. 1 demonstrates a sample of different loops where the left side demonstrates Reinforcing loop and the right side shows a Balancing loop.

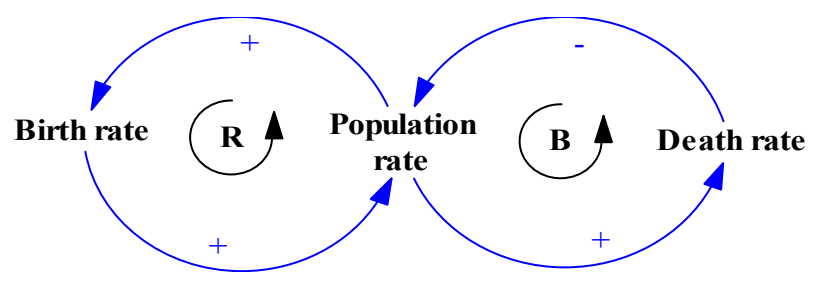

Fig. 1. Cause and effect loop

\section{The proposed model}

The proposed model of this paper uses systems dynamic to show the effects of various factors on supply chain management. Fig. 3 demonstrates the summary of our proposed model, 


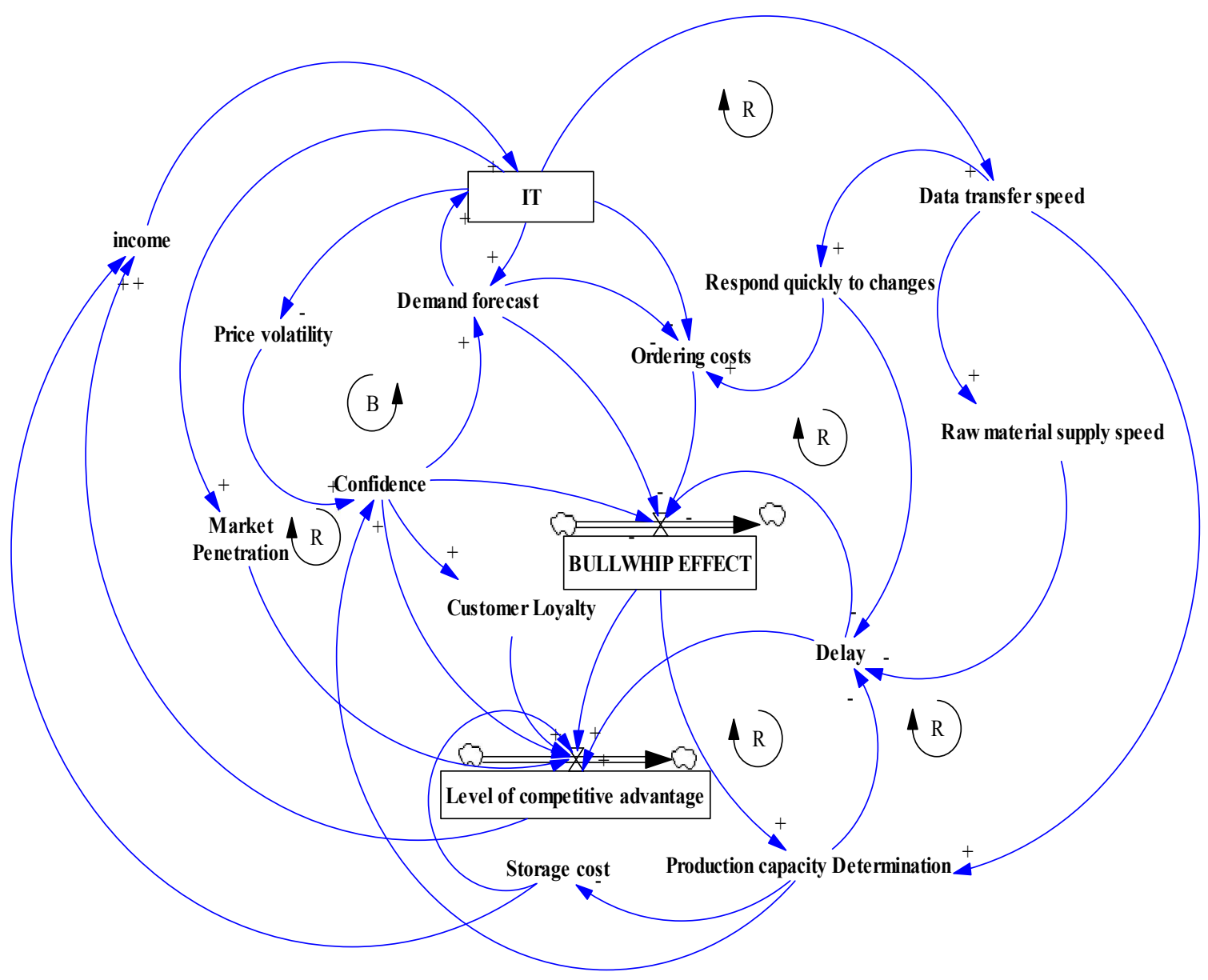

Fig. 2. The cause and effect diagram for bullwhip effect

As we can observe from Fig. 2, there are different factors influencing bullwhip effect on production planning and we need to measure the relative impact of these components. The survey indicates that as we get better information technology enhancement, we have better demand prediction, which reduces inventory expenses. The proposed study of this paper uses fuzzy DEMATEL to measure the effects of these factors. Table 1 summarizes the important factors extracted from Fig. 2.

Table 1

The summary of influencing factors on Bullwhip effect

\begin{tabular}{clcl}
\hline Variable & Effective factor & Variable & Effective factors \\
\hline A1 & BULLWHIP EFFECT & A 9 & Ordering costs \\
A 2 & Level of competitive advantage & A 10 & Demand forecast \\
A 3 & Customer Loyalty & A 11 & Price volatility \\
A 4 & Storage cost & A 12 & income \\
A 5 & Production capacity Determination & A 13 & It \\
A 6 & Delay & A 14 & Data transfer speed \\
A 7 & Market Penetration & A 15 & Respond quickly to changes \\
A 8 & Raw material supply speed & A 16 & Confidence \\
\hline
\end{tabular}

We first find the direct and indirect relationships among various components of the survey. Table 2 demonstrates the results of direct and indirect factors. 
Table 2

The summary of direct and indirect factors

\begin{tabular}{|c|c|c|c|c|c|c|c|c|c|c|c|c|c|c|c|c|}
\hline & 1 & 2 & 3 & 4 & 5 & 6 & 7 & 8 & 9 & 10 & 11 & 12 & 13 & 14 & 15 & 16 \\
\hline 1 & 0.026 & 0.211 & 0.008 & 0.062 & 0.29 & 0.075 & -0.012 & -0.017 & -0.010 & 0.005 & -0.011 & 0.083 & 0.018 & -0.007 & -0.017 & 0.088 \\
\hline 2 & -0.005 & -0.036 & -0.012 & -0.012 & -0.004 & -0.014 & 0.007 & -0.005 & 0.017 & 0.016 & 0.01 & 0.321 & 0.104 & 0.027 & -0.004 & -0.005 \\
\hline 3 & -0.023 & 0.224 & -0.030 & -0.016 & -0.020 & -0.021 & -0.008 & -0.012 & -0.006 & -0.009 & -0.010 & 0.067 & 0.015 & -0.004 & -0.012 & -0.017 \\
\hline 4 & -0.012 & 0.228 & -0.017 & -0.031 & -0.011 & -0.020 & 0.004 & -0.009 & 0.014 & 0.012 & 0.006 & 0.326 & 0.103 & 0.025 & -0.008 & -0.010 \\
\hline 5 & 0.196 & 0.268 & 0.07 & 0.249 & 0.022 & 0.305 & -0.014 & -0.022 & -0.011 & 0.049 & -0.005 & 0.15 & 0.037 & -0.004 & -0.022 & 0.338 \\
\hline 6 & 0.289 & 0.294 & -0.011 & 0.005 & 0.071 & -0.010 & -0.011 & -0.016 & -0.008 & -0.006 & -0.012 & 0.095 & 0.023 & -0.004 & -0.016 & 0.012 \\
\hline 7 & -0.023 & 0.224 & -0.015 & -0.016 & -0.020 & -0.021 & -0.022 & -0.012 & -0.006 & -0.009 & -0.010 & 0.067 & 0.015 & -0.004 & -0.012 & -0.017 \\
\hline 8 & 0.028 & 0.022 & -0.014 & -0.012 & -0.007 & 0.152 & -0.012 & -0.027 & -0.013 & -0.015 & -0.014 & -0.002 & -0.009 & -0.012 & -0.014 & -0.014 \\
\hline 9 & 0.153 & 0.009 & -0.010 & -0.002 & 0.031 & -0.004 & -0.012 & -0.013 & -0.027 & -0.013 & -0.014 & -0.004 & -0.009 & -0.012 & -0.014 & 0 \\
\hline 10 & 0.311 & 0.062 & 0.006 & 0.007 & 0.075 & 0.017 & -0.015 & -0.017 & -0.015 & -0.017 & 0.153 & 0.016 & -0.005 & -0.014 & -0.018 & 0.072 \\
\hline 11 & 0.121 & 0.126 & 0.076 & -0.008 & 0.019 & 0.048 & -0.013 & -0.016 & -0.013 & 0.046 & -0.019 & 0.035 & 0.002 & -0.011 & -0.016 & 0.336 \\
\hline 12 & 0.036 & 0.009 & -0.007 & -0.005 & 0.032 & 0.002 & 0.043 & 0.009 & 0.073 & 0.078 & 0.057 & -0.020 & 0.326 & 0.103 & 0.014 & 0.024 \\
\hline 13 & 0.145 & 0.084 & 0.004 & 0.012 & 0.127 & 0.038 & 0.143 & 0.044 & 0.234 & 0.252 & 0.187 & 0.02 & -0.025 & 0.315 & 0.061 & 0.097 \\
\hline 14 & 0.048 & 0.062 & 0.007 & 0.067 & 0.318 & 0.117 & -0.020 & 0.186 & -0.020 & -0.003 & -0.020 & 0.03 & -0.004 & -0.032 & 0.236 & 0.093 \\
\hline 15 & 0.032 & 0.044 & 0.007 & 0.054 & 0.252 & 0.065 & -0.014 & -0.016 & -0.014 & 0 & -0.013 & 0.023 & -0.002 & -0.012 & -0.031 & 0.075 \\
\hline 16 & 0.388 & 0.419 & 0.244 & 0.003 & 0.092 & 0.172 & -0.017 & -0.024 & -0.014 & 0.159 & 0.012 & 0.135 & 0.031 & -0.008 & -0.025 & 0.009 \\
\hline
\end{tabular}

In addition, Table 3 demonstrates details of our computations for the proposed study of this paper Fig. 3 presents details of our results.

Table 3

The summary R, J, R+J and R-J

\begin{tabular}{ccccc}
\hline & $\mathrm{R}$ & $\mathrm{J}$ & $\mathrm{R}+\mathrm{J}$ & $\mathrm{R}-\mathrm{J}$ \\
\hline A1 & 0.791 & 1.712 & 2.503 & -0.920 \\
A2 & 0.405 & 2.250 & 2.655 & -1.846 \\
A3 & 0.120 & 0.305 & 0.425 & -0.185 \\
A4 & 0.600 & 0.358 & 0.958 & 0.243 \\
A5 & 1.605 & 1.268 & 2.873 & 0.336 \\
A6 & 0.695 & 0.901 & 1.596 & -0.207 \\
A7 & 0.120 & 0.026 & 0.145 & 0.094 \\
A8 & 0.039 & 0.032 & 0.071 & 0.007 \\
A9 & 0.059 & 0.180 & 0.239 & -0.121 \\
A10 & 0.617 & 0.546 & 1.163 & 0.071 \\
A11 & 0.713 & 0.297 & 1.010 & 0.416 \\
A12 & 0.773 & 1.340 & 2.113 & -0.567 \\
A13 & 1.739 & 0.622 & 2.360 & 1.117 \\
A14 & 1.067 & 0.348 & 1.415 & 0.720 \\
A15 & 0.451 & 0.104 & 0.554 & 0.347 \\
A16 & 1.577 & 1.081 & 2.658 & 0.496 \\
\hline
\end{tabular}

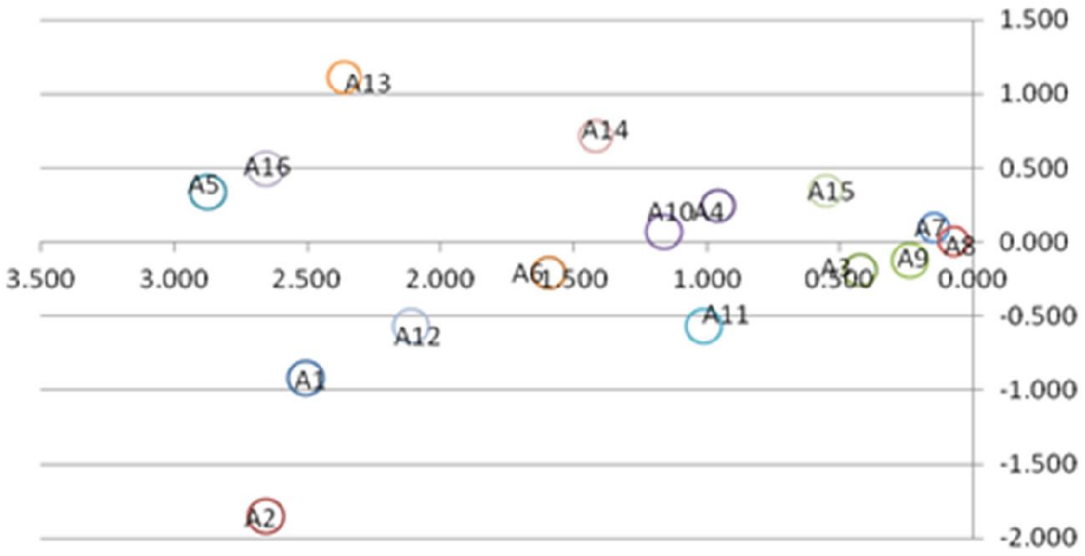

Fig. 3. The summary of the position of various factors influencing Bullwhip effect 
Fig. 4 summarizes the effects of different factors on bullwhip effect based on the implementation of fuzzy DEMATEL.

0.315

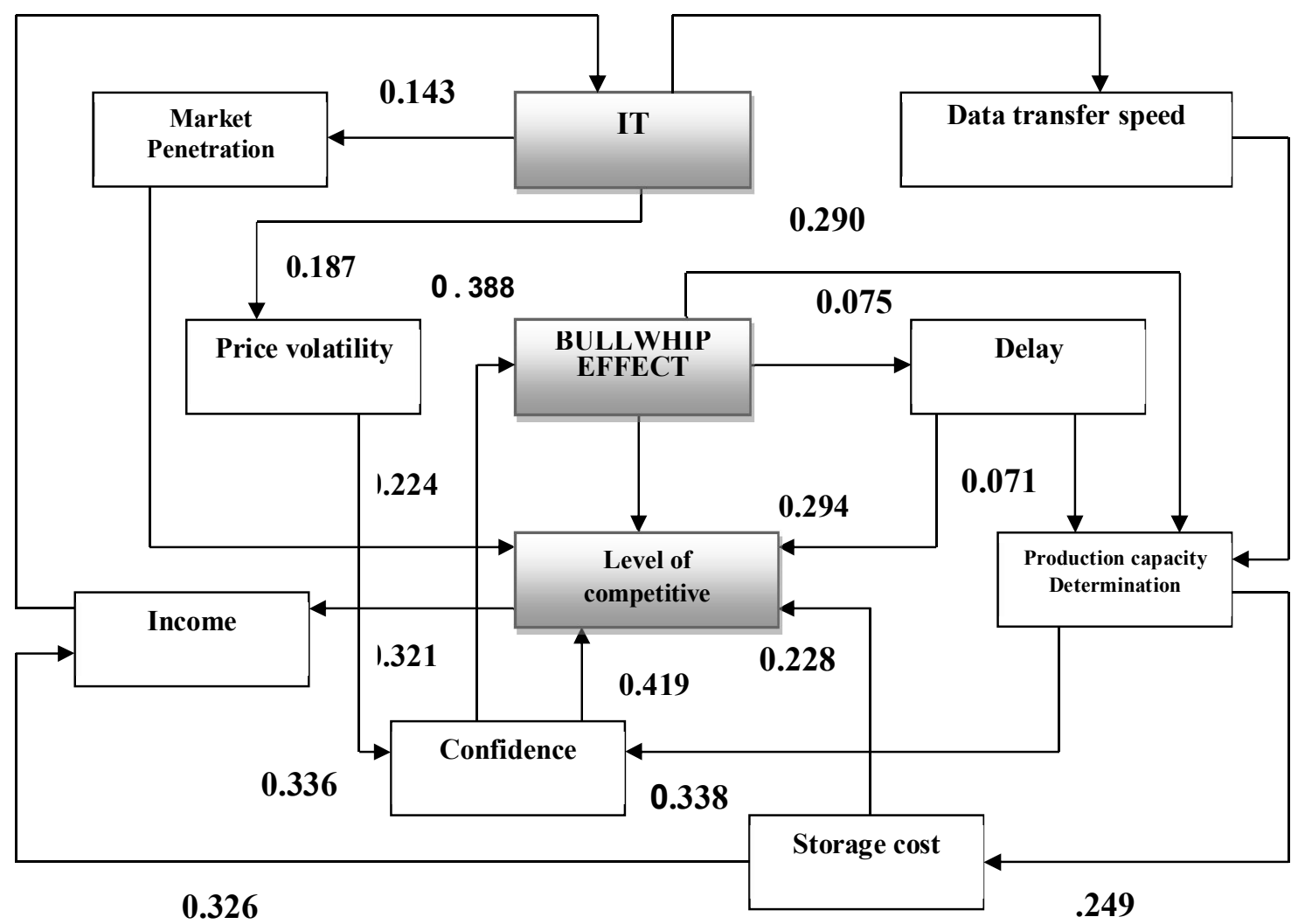

0.318

Fig. 3. The summary of the position of various factors influencing Bullwhip effect

As we can observe from the results of Fig. 3, information technology expedites data transformation on one side and it could increase market penetration on the other side. Bullwhip effect influences production capacity determination and reduces customer's confidence, significantly.

\section{Conclusion}

During the past three decades, there have been tremendous changes on information technology in the world and many business owners apply different features of information technology to reduce the cost of their products and services. There is a growing concern that information technology could help business owners find better access to customer's demand and plan ahead of time. This paper has presented an investigation to confirm the positive effect of information technology on reducing bullwhip effect. The results of this survey have also confirmed that any reduction on bullwhip effect could have positive impact on economy building better infrastructure to reduce inventory expenditures, increase productivity and efficiency of organizations.

\section{Acknowledgment}

The authors would like to thank the anonymous referees for their construction comments on earlier version of this work. 


\section{References}

Aggelogiannaki, E., \& Sarimveis, H. (2008). Design of a novel adaptive inventory control system based on the online identification of lead time. International Journal of Production Economics, 114(2), 781-792.

Caplin, A. S. (1985). The variability of aggregate demand with (S, s) inventory policies. Econometrica: Journal of the Econometric Society, 1395-1409.

Croxton, K. L., Garcia-Dastugue, S. J., Lambert, D. M., \& Rogers, D. S. (2001). The supply chain management processes. The International Journal of Logistics Management, 12(2), 13-36.

Chou, D. C., Tan, X., \& Yen, D. C. (2004). Web technology and supply chain management. Information Management \& Computer Security, 12(4), 338-349.

Croom, S. R. (2005). The impact of e-business on supply chain management: an empirical study of key developments. International Journal of Operations \& Production Management, 25(1), 55-73.

Day, G. S. (1984). Strategic market planning: The pursuit of competitive advantage. St-Paul, Minnesota: West Publishing Company.

Dalalah,D., Hayajneh, M., \& Batieha, F. (2011). A fuzzy multi-criteria decision making model for supplier selection. Expert Systems with Applications, 38, 8384-8391.

Demeter, K., Gelei, A., \& Jenei, I. (2006). The effect of strategy on supply chain configuration and management practices on the basis of two supply chains in the Hungarian automotive industry. International Journal of Production Economics, 104(2), 555-570.

Disney, S. M., Towill, D. R., \& Van de Velde, W. (2004). Variance amplification and the golden ratio in production and inventory control. International Journal of Production Economics, 90(3), 295-309.

Fontela, E., \& Gabus, A. (1976). The DEMATEL observer. DEMATEL 1976 Report. Switzerland, Geneva: Battelle Geneva Research Center.

Forrester, J. W. (1961). Industrial Dynamics. Pegasus Communications. ISBN 1-883823-36-6.

Forrester, J. W. (1994). System dynamics, systems thinking, and soft OR. System Dynamics Review, 10(2-3), 245-256.

Gabus, A., \& Fontela, E. (1973). Perceptions of the world problematique: communication procedure, communicating with those bearing collective responsibility. DEMATEL Report No. 1. Geneva, Switzerland: Battelle Geneva Research Center.

Geary, S., Disney, S. M., \& Towill, D. R. (2006). On bullwhip in supply chains-historical review, present practice and expected future impact. International Journal of Production Economics, 101(1), 2-18.

Ha, S. H., \& Krishnan, R. (2008). A hybrid approach to supplier selection for the maintenance of a competitive supply chain. Expert Systems with Applications, 34(2), 1303-1311.

Hoffman, N. P. (2000). An examination of the "sustainable competitive advantage" concept: past, present, and future. Academy of Marketing Science Review, 4, 1-16.

Huang, C. Y., Shyu, J. Z., \& Tzeng, G. H. (2007). Reconfiguring the innovation policy portfolios for Taiwan's SIP Mall industry. Technovation, 27, 744-765.

Kim, J. G., Chatfield, D., Harrison, T. P., \& Hayya, J. C. (2006). Quantifying the bullwhip effect in a supply chain with stochastic lead time. European Journal of operational research, 173(2), 617636.

Lee, H. L., Padmanabhan, V., \& Whang, S. (1997). The bullwhip effect in supply chains. Sloan management review, 38(3), 93-102.

Lee, W. S., Huang, A. Y., Chang, Y. Y., \& Cheng, C. M. (2011). Analysis of decision making factors for equity investment by DEMATEL and Analytic Network Process. Expert Systems with Applications, 38(7), 8375-8383.

Lo, C. C., \& Chen, W. J. (2012). A hybrid information security risk assessment procedure considering interdependences between controls. Expert Systems with Applications, 39(1), 247-257.

Lu, L., \& Wang, G. (2008). A study on multi-agent supply chain framework based on network economy. Computers \& Industrial Engineering, 54(2), 288-300. 
Luong, H. T. (2007). Measure of bullwhip effect in supply chains with autoregressive demand process. European Journal of Operational Research, 180(3), 1086-1097.

Machuca, J. A., \& Barajas, R. P. (2004). The impact of electronic data interchange on reducing bullwhip effect and supply chain inventory costs. Transportation Research Part E: Logistics and Transportation Review, 40(3), 209-228.

Mestan, E., Türkay, M., \& Arkun, Y. (2006). Optimization of operations in supply chain systems using hybrid systems approach and model predictive control. Industrial \& engineering chemistry research, 45(19), 6493-6503.

Miragliotta, G. (2006). Layers and mechanisms: A new taxonomy for the bullwhip effect. International Journal of Production Economics, 104(2), 365-381.

Najmi, A \& Makui, A. (2010). Providing hierarchical approach for measuring supply chain performance using AHP and DEMATEL methodologies. International Journal of Industrial Engineering Computations, 1(2), 199-212.

Opricovic, S., Tzeng, G.H. (2003). Defuzzification within a multicriteria decision model. International Journal of Uncertainty, Fuzziness and Knowledge-based Systems, 11, 635-652.

Sofiyabadi, J., movahedi, M \& Nasab, S. (2012). Strategic orientation in evaluation of supply chain activities. Management Science Letters , 2(5), 1785-1794.

Zadeh, L.A. (1975). The concept of a linguistic variable and its application to approximate reasoning. Information Science, 8, 199-249. 